Check for updates

Cite this: J. Mater. Chem. A, 2020, 8 5995

Received 13th January 2020

Accepted 3rd March 2020

DOI: $10.1039 / \mathrm{d} 0 \operatorname{ta} 00520 \mathrm{~g}$

rsc.li/materials-a

\section{The role of connectivity in significant bandgap narrowing for fused-pyrene based non-fullerene acceptors toward high-efficiency organic solar cellst}

\author{
Shungang Liu,,$^{\mathrm{ab}}$ Wenyan Su, $\$^{\mathrm{c}}$ Xianshao Zou, ${ }^{\mathrm{d}}$ Xiaoyan Du, ${ }^{\mathrm{e}}$ Jiamin Cao, (D) *ab \\ Nong Wang, ${ }^{\mathrm{b}}$ Xingxing Shen, ${ }^{\mathrm{f}}$ Xinjian Geng, (D) ${ }^{\mathrm{b}}$ Zilong Tang, ${ }^{\mathrm{a}}$ Arkady Yartsev, (D)d \\ Maojie Zhang, (D) ${ }^{* c}$ Wolfgang Gruber, ${ }^{9}$ Tobias Unruh, ${ }^{9}$ Ning Li, (D) \\ Donghong Yu, (D) *hi Christoph J. Brabec ${ }^{e}$ and Ergang Wang (D) *bj
}

\begin{abstract}
Great attention has been paid to developing low bandgap non-fullerene acceptors (NFAs) for matching wide bandgap donor polymers to increase the photocurrent and therefore the power conversion efficiencies (PCEs) of NFA organic solar cells, while pyrene-core based acceptor-donor-acceptor (AD-A) NFAs have been mainly reported via the 2,9-position connection due to their bisthieno $\left[3^{\prime}, 2^{\prime}-b^{\prime}\right]$ thienyl[a,h]pyrene fused via a five-membered ring bridge at the ortho-position of pyrene as the representative one named FPIC5, which has prohibited further narrowing their energy gap. Herein, an acceptor FPIC6 was exploited by creating the 1,8-position connection through fusing as bisthieno[ $3^{\prime}, 2^{\prime}$ $\left.b^{\prime}\right]$ thienyl[f-g,m-n]pyrene linked at the bay-position via a six-membered bridge, with enhanced pushpull characteristics within such A-D-A structure. As a structural isomer of FPIC5, FPIC6 exhibited a much lower bandgap of $1.42 \mathrm{eV}(1.63 \mathrm{eV}$ for FPIC5). Therefore, the photocurrent and PCE of PTB7Th:FPIC6 cells were improved to $21.50 \mathrm{~mA} \mathrm{~cm}{ }^{-2}$ and $11.55 \%$, respectively, due to the balanced mobilities, better photoluminescence quenching efficiency and optimized morphology, which are both $\sim 40 \%$ better than those of PTB7-Th:FPIC5 cells. Our results clearly proved that a pyrene fused core with 1,8-position connection with electron-withdrawing end groups instead of 2,9-position connection is an efficient molecular design strategy to narrow the optical bandgap and improve the photovoltaic performance of NFA based OSCs.
\end{abstract}

\section{Introduction}

A breakthrough milestone for boosting the performance of organic solar cells (OSCs) in 2015 was the development of a non-fullerene acceptor (NFA) abbreviated as ITIC by Lin and Zhan et al. and the follow-on derivatives with their concept of

fused-ring electron acceptors (FREAs). ${ }^{1-3}$ Such a breakthrough is based on not only the significantly improved complementary optical absorption matches between the donor and acceptor materials and the finely tunable LUMO levels of NFAs, but also their high electron mobility. ${ }^{4-17}$ Therefore such a perfect combination of wide bandgap polymers as the donor

${ }^{a}$ Key Laboratory of Theoretical Organic Chemistry and Functional Molecule of Ministry of Education, Hunan Provincial Key Laboratory of Controllable Preparation and Functional Application of Fine Polymers, School of Chemistry and Chemical Engineering, Hunan University of Science and Technology, Xiangtan 411201, China.E-mail:minjiacao@163.com

${ }^{b}$ Department of Chemistry and Chemical Engineering/Applied Chemistry, Chalmers University of Technology, Göteborg SE-41296, Sweden. E-mail: ergang@chalmers.se 'Laboratory of Advanced Optoelectronic Materials, College of Chemistry, Chemical Engineering and Materials Science, Soochow University, Suzhou 215123, China. E-mail: mjzhang@suda.edu.cn

${ }^{d}$ NanoLund and Division of Chemical Physics, Lund University, Box 124, Lund 22100, Sweden

'Institute of Materials for Electronics and Energy Technology (i-MEET), Department of Materials Science and Engineering, Friedrich-Alexander-Universität ErlangenNürnberg, Martensstrasse 7, 91058 Erlangen, Germany

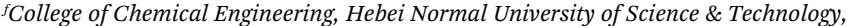
Qinhuangdao 066004, China

IInstitute of Crystallography and Structural Physics, Department of Physics, Friedrich-Alexander-Universität Erlangen-Nürnberg, Staudtstr. 3, 91058 Erlangen, Germany

${ }^{h}$ Department of Chemistry and Bioscience, Aalborg University, Aalborg East, DK9220, Denmark.E-mail: yu@bio.aau.dk

${ }^{i}$ Sino-Danish Center for Education and Research, Aarhus, DK-8000, Denmark

${ }^{j}$ School of Materials Science and Engineering, Zhengzhou University, Zhengzhou 450001, China

$\dagger$ Electronic supplementary information (ESI) available. See DOI: $10.1039 /$ d0ta00520g

$\$$ These authors contributed equally to this work. 
and low bandgap NFAs has pushed the efficiency of OSCs up to $18 \% .^{18-21}$

Among the state-of-the-art donor-core moieties for FREAs such as indacenodithiophene (IDT), indacenodithieno[3,2- $b]$ thiophene (IDTT), oligomeric IDT, and their structural analogues, pyrene, as a cheap and commercially available polycyclic aromatic hydrocarbon composed of four fused benzene rings, has gained great attention in the rational molecular design of organic semiconductors due to its good structural planarity, excellent thermal stability, largely decreased ionization potential, extensive electron delocalization and fast charge-transport ability. ${ }^{22-28}$ As a result, pyrene derivatives usually exhibit strong $\pi-\pi$ stacking, high degree of crystallinity, and enhanced charge carrier mobilities, and therefore have been widely used in organic field effect transistors (OFETs), organic light emitting diodes (OLEDs), and hole-transporting materials for perovskite solar cells and OSCs. ${ }^{27-31}$ This gave birth to a medium-bandgap FPIC (termed as FPIC5 in this paper, Scheme 1) by Lian and Zhan et al. in 2018, which was based on pyrene fused with two thieno[3,2- $b]$ thiophenes via five-member-ring bridges of di(parahexyl)phenylcyclopentadienyl at the two ortho-positions of pyrene $[a, h]$ (2,9-positions). ${ }^{32}$ The optical bandgap of FPIC5 was found to be medium at $1.63 \mathrm{eV}$, leading to a low short-circuit current density $\left(J_{\mathrm{SC}}\right)$ of $15.3 \mathrm{~mA} \mathrm{~cm} \mathrm{~cm}^{-2}$ with a moderate PCE of 8.45\% for solar cells based on PTB7-Th:FPIC5. Another two NFAs with the pyrene core connecting with end groups via 2,9-positions named Py-1 and Py-2 also exhibited a wide bandgap of 1.95 and $1.97 \mathrm{eV}$ respectively, leading to low $J_{\mathrm{SC}}$ and $\mathrm{PCE}^{33}$ On the other hand, "DTP-IC-4Ph" (dithieno[f-g,m-n](di(para-hexyl) phenyl)cyclohexapyrene-IC) from Guo et $a .^{34}$ with the pyrene core connecting with end groups via 1,8-positions presented a notably red-shifted absorption spectrum and thus a clearly improved $J_{\mathrm{SC}}$ of $17.32 \mathrm{~mA} \mathrm{~cm}^{-2}$ and PCE of $10.37 \%$. However, the reasons for the red-shifted spectra and how the connection position of the pyrene core can influence the properties of the resulting molecules have not been systematically studied.

Above all, isomerization of pyrene core based NFAs with connection varying from 2,9-positions to 1,8-positions could dramatically enhance both conjugation and connectivity, leading to low-bandgap conjugated molecules. This inspired our design idea on developing a new small molecule acceptor FPIC6 in this work, using pyrene condensed with two thieno $[3,2-b]$ thiophenes via six-membered ring bridges as the central core and 2-(5,6-difluoro-3-oxo-2,3-dihydro- $1 \mathrm{H}$-inden-1-ylidene) malononitrile (2FIC) as the end-groups through 1,8 sites (Scheme 1). It is noteworthy that FPIC6 with its 1,8-position connection exhibited an $\sim 119 \mathrm{~nm}$ red-shifted absorption when compared to the reported isomer FPIC5 with 2,9-position connection, leading to a narrow bandgap of $1.42 \mathrm{eV}$ (obtained from optical absorption) and $1.53 \mathrm{eV}$ (determined by CV). As a result, simple binary PTB7-Th:FPIC6 solar cells exhibited a much higher photocurrent (21.5 vs. $15.3 \mathrm{~mA} \mathrm{~cm}^{-2}$ ) and PCE $(11.55 \%$ vs. $8.45 \%)$ than its structural isomer FPIC5.

\section{Results and discussion}

\subsection{Materials synthesis and characterization}

The synthetic route to FPIC6 is shown in Scheme 1, and the experimental details are presented in the Experimental section and ESI. $\dagger$ A Suzuki coupling reaction between 1,6-bis $(4,4,5,5-$
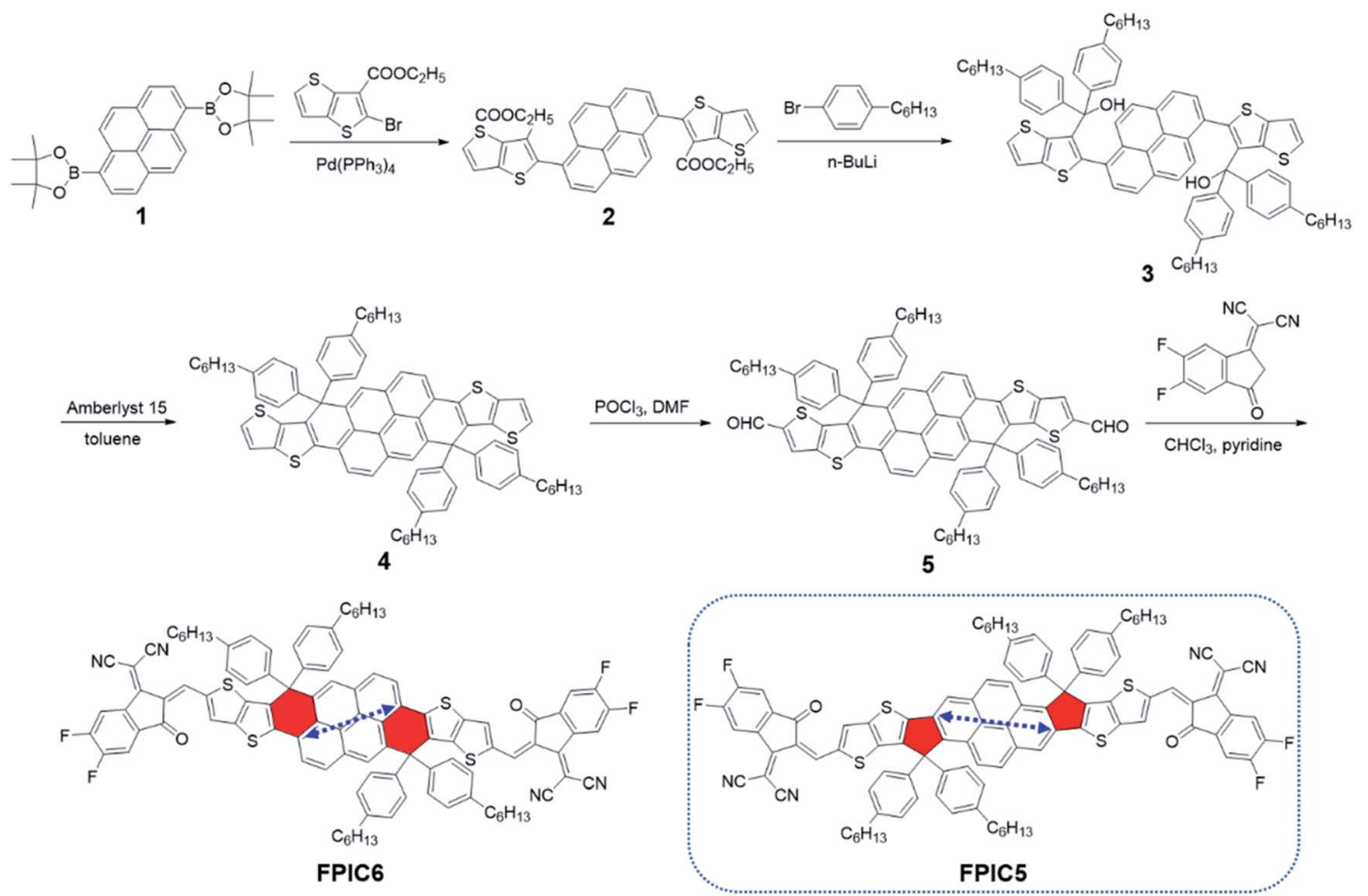

Scheme 1 Synthetic route to small molecule acceptor FPIC6 and the chemical structure of FPIC5 
tetramethyl-1,3,2-dioxaborolan-2-yl)pyrene (1) ${ }^{35}$ and ethyl 2bromothieno $[3,2-b]$ thiophene-3-carboxylate could give diethyl 2,2'-(pyrene-1,6-diyl)bis(thieno[3,2- $b]$ thiophene-3-carboxylate)

(2) with a yield of $88.7 \%$. Compound 2 was reacted with 4 -hexylphenyl lithium to give the tertiary alcohol 3, which could be converted to decacyclic compound 4 via the Amberlyst 15 assisted Friedel-Crafts alkylation reaction. Then, the dialdehyde compound $\mathbf{5}$ was prepared by means of a VilsmeierHaack reaction of compound $\mathbf{4}$ with phosphorus oxychloride $\left(\mathrm{POCl}_{3}\right)$ and $\mathrm{N}, \mathrm{N}$-dimethylformamide (DMF) with a yield of $84.1 \%$. A Knoevenagel condensation reaction between compound $\mathbf{5}$ and 2FIC afforded the final product FPIC6 (yield: 77.0\%). The chemical structures of intermediates and FPIC6, and their purities were confirmed by NMR and mass spectra. FPIC6 is readily soluble in common organic solvents such as dichloromethane, chloroform and chlorobenzene. As shown in Fig. $\mathrm{S} 1, \dagger$ the decomposition temperature $\left(T_{\mathrm{d}}, 5 \%\right.$ wt loss) of FPIC6 is $37{ }^{\circ} \mathrm{C}$, indicating its excellent thermal stability for photovoltaic applications.

\subsection{Optical properties}

For the UV-vis-NIR absorption spectra of FPIC6 both in dilute chloroform solution and as thin films (as displayed in Fig. 1a), compared with the weak absorption for the $\pi-\pi^{*}$ transition below $500 \mathrm{~nm}$, there is a clear main peak at $723 \mathrm{~nm}$ for its solution arising from the intramolecular charge transfer (ICT) from the electron-donating pyrene core to the terminal electron accepting moieties. As shown in Fig. S2, $\uparrow$ the temperaturedependent UV-vis absorption of FPIC6 in solution discloses slight blue-shifts ranging from 2 to $10 \mathrm{~nm}$ with increasing temperature from $20{ }^{\circ} \mathrm{C}$ to $100{ }^{\circ} \mathrm{C}$, indicating that there is no evidence of even moderate molecular aggregation in the dilute solutions, and all the main peaks originated from the ICT as stated above. When seeing the very much alike absorption spectrum of its counterpart FPIC5 in the solution, ${ }^{32}$ the main peak is evidently red-shifted from $645 \mathrm{~nm}$ for FPIC5 to $723 \mathrm{~nm}$ for FPIC6 (with a molar extinction coefficient of $1.73 \times$ $10^{5} \mathrm{M}^{-1} \mathrm{~cm}^{-1}$ ). This reveals both stronger electron push-pull effects and more extended conjugation through improved connectivity (will be discussed more later on) and therefore an efficiently narrowed energy bandgap for FPIC6 compared to the five-membered ring fused FPIC5. Meanwhile, the FPIC6 film exhibits strong absorption in the region of $600-870 \mathrm{~nm}$ with an absorption peak at $785 \mathrm{~nm}$. From solution to thin films, FPIC6 exhibits a large bathochromic shift of $62 \mathrm{~nm}$, demonstrating strong intermolecular interaction in its solid state. ${ }^{36-44}$ It is noteworthy that the absorption peak is significantly $119 \mathrm{~nm}$ redshifted, compared with its isomer FPIC5 (Table 1). This reflects that FPIC6 with the six-membered ring bridge possesses a more effective intramolecular charge transfer effect compared to fivemembered ring bridged FPIC5. ${ }^{32}$ The optical bandgap $\left(E_{\mathrm{g}}^{\mathrm{opt}}\right)$ of FPIC6 was calculated to be $1.42 \mathrm{eV}$ from the absorption edge of $871 \mathrm{~nm}$ in films, which is significantly narrowed in comparison with $1.63 \mathrm{eV}$ for its isomer FPIC5. As a result, FPIC6 possesses complementary absorption spectra to PTB7-Th (Fig. 1a), which is beneficial for higher photocurrent.

\subsection{Electrochemical properties and theoretical calculations}

The electrochemical properties of FPIC6 were investigated by cyclic voltammetry (CV). As shown in Fig. S3, $\uparrow$ FPIC6 possesses the onset oxidation potential $\left(E_{\mathrm{ox}}^{\mathrm{on}}\right)$ of $0.64 \mathrm{~V}$, corresponding to the HOMO energy level at $-5.44 \mathrm{eV}$, while the onset reduction potential ( $E_{\text {red }}^{\text {on }}$ ) of FPIC6 is $-0.89 \mathrm{~V}$, corresponding to the LUMO energy level of $-3.91 \mathrm{eV}$. Compared with FPIC5, the reduced bandgap of FPIC6 mainly results from the more significantly lifted HOMO energy level rather than the slightly increased LUMO level, which is a very favourable way for highly efficient solar cells without sacrificing open-circuit voltage $\left(V_{\mathrm{OC}}\right)$. Meanwhile, the energy levels of FPIC6 exhibited a good match with the well-known polymer donor PTB7-Th (Fig. 1c).

Density functional theory (DFT) calculations at the B3LYP/6$31 \mathrm{G}(\mathrm{d}, \mathrm{p})$ level were performed to study the geometric and electronic properties of FPIC6 and FPIC5 (Fig. S4 and S5 $\dagger$ ). Unlike coplanar FPIC5, FPIC6 possesses a twisted molecular conformation, with the dihedral angles of $\sim 10^{\circ}$ between the core unit and terminal 2FIC units, which could nicely contribute to its good solubility in organic solvents. In comparison with FPIC5, the HOMO orbital of FPIC6 is further (a)

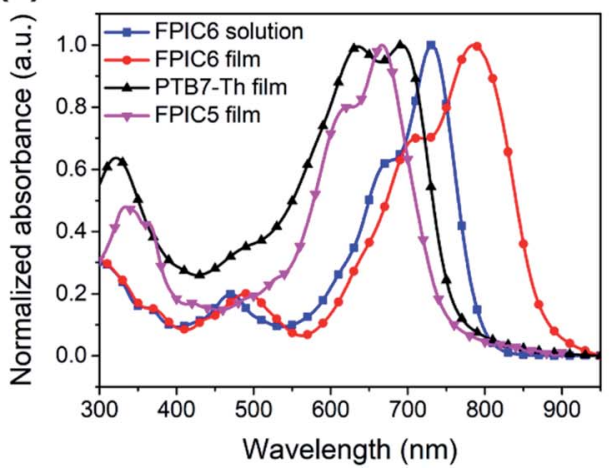

(b)

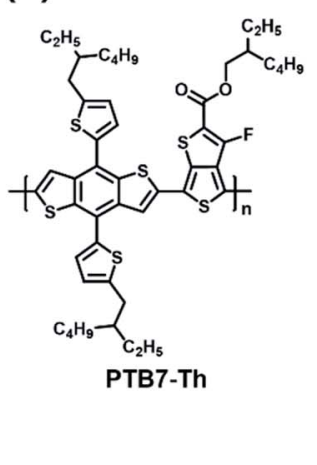

(c)

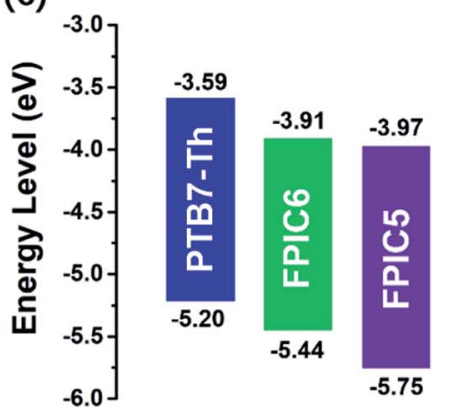

Fig. 1 Absorption spectra of FPIC6, PTB7-Th and FPIC5 (a), chemical structure of PTB7-Th (b), and energy level diagrams of FPIC6, PTB7-Th and FPIC5 (c). 
Table 1 Optical and electrochemical properties of FPIC6 and FPIC5

\begin{tabular}{|c|c|c|c|c|c|c|c|c|}
\hline Acceptor & $\begin{array}{l}\lambda_{\mathrm{sol}} \\
{[\mathrm{nm}]}\end{array}$ & $\begin{array}{l}\lambda_{\text {film }} \\
{[\mathrm{nm}]}\end{array}$ & $\begin{array}{l}\lambda_{\text {onset }} \\
{[\mathrm{nm}]}\end{array}$ & $E_{\mathrm{g}}^{\mathrm{opt} b}[\mathrm{eV}]$ & $\mathrm{HOMO}^{c}[\mathrm{eV}]$ & $\mathrm{LUMO}^{d}[\mathrm{eV}]$ & $\operatorname{HOMO}^{e}[\mathrm{eV}]$ & $\operatorname{LUMO}^{e}[\mathrm{eV}]$ \\
\hline FPIC6 & 723 & 785 & 871 & 1.42 & -5.44 & -3.91 & -5.37 & -3.44 \\
\hline
\end{tabular}

${ }^{a}$ These data are from ref. $29 .{ }^{b} E_{\mathrm{g}}^{\mathrm{opt}}=1240 / \lambda_{\text {onset }}{ }^{c} \mathrm{HOMO}=-\left(E_{\mathrm{Ox}}^{\mathrm{on}}-4.8\right) \mathrm{eV} \cdot{ }^{d} \mathrm{LUMO}=-\left(E_{\mathrm{red}}^{\mathrm{on}}-4.8\right) \mathrm{eV} .{ }^{e}$ Calculated from DFT.

localized on the central core units, which satisfactorily follows the design idea of a more fused six-membered ring bridge for this molecule. The LUMO orbital is mainly distributed along the whole molecular backbone, from thieno[3,2-b]thiophene-fused pyrene as a core to the terminal electron-withdrawing units, suggesting a more effective intramolecular charge transfer effect in FPIC6. ${ }^{45}$ This observation agrees well with the report, in which it is described that the connection through 1,8-positions (indicated by the blue arrow in the structure of FPIC6 in Scheme 1) of pyrene has much higher conductance than that through 2,9-positions (indicated by the blue arrow in the structure of FPIC5 in Scheme 1) of it. ${ }^{46}$ Therefore, the improved connectivity in FPIC6 can explain its extended conjugation, enhanced ICT effect, and narrower bandgap as well as red-shifted absorption spectrum. Moreover, the calculated HOMO/LUMO energy levels are $-5.37 /-3.44 \mathrm{eV}$ for FPIC6 and $-5.61 /-3.39 \mathrm{eV}$ for FPIC5. FPIC6 showed a similar LUMO level to FPIC5, but a $0.24 \mathrm{eV}$ higher HOMO level and a narrower bandgap. The trend is consistent with the $\mathrm{CV}$ measurement results.

\subsection{Photovoltaic performance}

Inverted solar cells with the structure of ITO/ZnO/PFN-Br/PTB7Th:FPIC6 $/ \mathrm{MoO}_{3} / \mathrm{Al}$ were fabricated to investigate the photovoltaic performance of FPIC6, and a well-known D-A polymer PTB7-Th was chosen as the donor material for the reasons mentioned above. As shown in Table S2, $\dagger$ diphenylethane (DPE), 1,8-diiodooctane (DIO), and especially 1-chloronaphthalene $(\mathrm{CN})$ were used as processing additives to optimize the microstructure morphology as well as the photovoltaic performance of PTB7-Th:FPIC6 cells. Without CN, the solar cell just achieved a reasonable PCE of 9.11\%, with a $V_{\mathrm{OC}}$ of $0.79 \mathrm{~V}$, a $J_{\mathrm{SC}}$ of $20.16 \mathrm{~mA} \mathrm{~cm}^{-2}$, and a fill factor (FF) of 0.58 (Fig. $2 \mathrm{a}$ and Table 2). The cells processed with $1 \% \mathrm{CN}$ ( $\mathrm{vol} / \mathrm{vol})$ in chloroform have achieved the highest PCE of $11.55 \%$, with a $V_{\mathrm{OC}}$ of $0.79 \mathrm{~V}$, a $J_{\mathrm{sC}}$ of $21.50 \mathrm{~mA} \mathrm{~cm}^{-2}$, and a FF of 0.67 . On the other hand, the isomer FPIC5 based OSCs with the same donor PTB7-Th exhibited a moderate PCE of $8.45 \%$ with a similar $V_{\mathrm{OC}}$ of $0.755 \mathrm{~V}$, but a much lower $J_{\mathrm{SC}}$ of $15.3 \mathrm{~mA} \mathrm{~cm}{ }^{-2} .{ }^{32}$ According to the formula $E_{\text {loss }}=E_{\mathrm{g}}^{\mathrm{opt}}-e V_{\mathrm{OC}}{ }^{47,48}$ the corresponding energy loss ( $\left.E_{\text {loss }}\right)$ of FPIC6 is $0.63 \mathrm{eV}$, which is much lower than that of FPIC5 $(0.88 \mathrm{eV})$. The enhanced photovoltaic performance of the optimized devices can be derived from the simultaneously enhanced $J_{\mathrm{SC}}$ and FF. As shown in Fig. $2 \mathrm{~b}$, by adding $\mathrm{CN}$ as the processing additive, the external quantum efficiency (EQE) responses were improved in the range of $400-760 \mathrm{~nm}$. The current density integrated from the EQE curve of the champion cells processed with $1 \% \mathrm{CN}$ is $20.53 \mathrm{~mA} \mathrm{~cm}{ }^{-2}$, which agrees well with the $J_{\mathrm{SC}}$ value from $J-V$ measurements. The much higher and broader EQEs can well explain their much higher photocurrent as compared to PTB7-Th:FPIC5 cells with a $J_{\mathrm{SC}}$ of $15.1 \mathrm{~mA} \mathrm{~cm}{ }^{-2}$. Moreover, PTB7-Th:FPIC6 cells with $0.5-1.5 \%$ CN exhibited an $\sim 25 \mathrm{~nm}$ blue-shift of EQE when compared to that of the devices without CN. This phenomenon is far less common in OSCs. These blue-shifted EQEs may originate from the reduced packing/aggregation of FPIC6 in the blend film with $1 \% \mathrm{CN}^{49-52}$

\subsection{Molecular orientation and crystallinity}

To confirm this hypothesis, the absorption of PTB7-Th:FPIC6 blend films was also recorded. As shown in Fig. S6, $\uparrow$ the PTB7- (a)

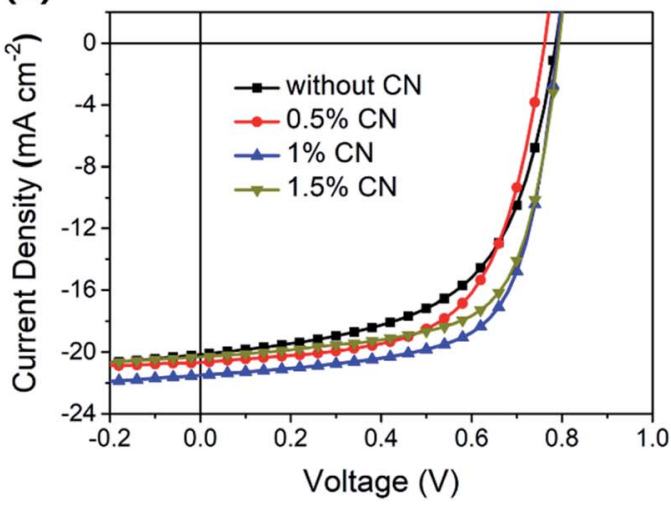

(b)

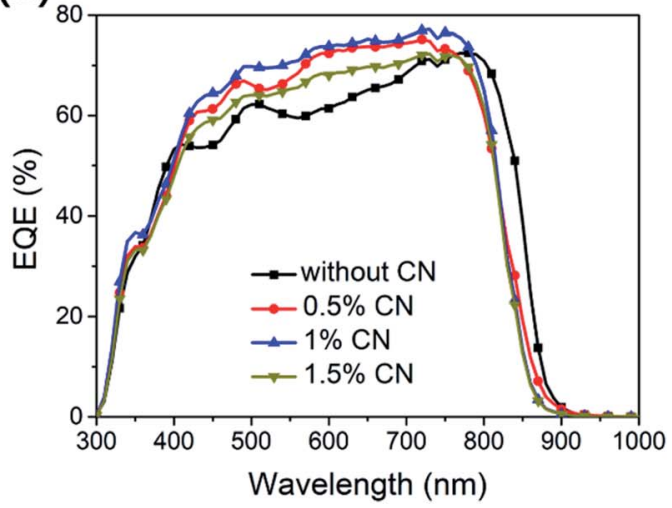

Fig. 2 J-V curves (a) and EQE spectra (b) of OSCs based on PTB7-Th:FPIC6. 
Table 2 Photovoltaic performance of the solar cells based on PTB7-Th:FPIC6

\begin{tabular}{llllll}
\hline $\mathrm{CN}[\mathrm{vol} \%]$ & $V_{\mathrm{OC}}[\mathrm{V}]$ & $J_{\mathrm{SC}}\left[\mathrm{mA} \mathrm{cm}^{-2}\right]$ & $\mathrm{FF}$ & $\mathrm{PCE}^{a}[\%]$ & $J_{\mathrm{EQE}}\left[\mathrm{mA} \mathrm{cm}^{-2}\right]$ \\
\hline 0 & $0.79(0.78 \pm 0.01)$ & $20.16(20.14 \pm 0.02)$ & $0.58(0.58 \pm 0.02)$ & $9.11(9.10 \pm 0.01)$ & 19.43 \\
0.5 & $0.76(0.75 \pm 0.01)$ & $20.68(20.65 \pm 0.03)$ & $0.62(0.60 \pm 0.02)$ & $9.91(9.89 \pm 0.02)$ & 20.05 \\
1 & $0.79(0.78 \pm 0.01)$ & $21.50(21.46 \pm 0.04)$ & $0.67(0.66 \pm 0.01)$ & $11.55(11.52 \pm 0.03)$ & 20.53 \\
1.5 & $0.79(0.78 \pm 0.01)$ & $20.31(20.28 \pm 0.03)$ & $0.67(0.64 \pm 0.03)$ & $10.75(10.74 \pm 0.01)$ & 19.12
\end{tabular}

${ }^{a}$ The average values in the parentheses are from 20 devices.

Th:FPIC6 blend film cast from its chloroform solution without CN showed an overall blue-shifted absorption compared to that of the neat FPIC6 film. The shoulder peak at $775 \mathrm{~nm}$ was plainly weakened, revealing the interfered $\pi-\pi$ stacking of FPIC6 in the presence of PTB7-Th, which in turn dramatically enhanced the ICT of FPIC6 as indicated by the sharp increase of the peak at $680 \mathrm{~nm}$. As for the blend film cast from the solution with 1\% CN as an additive, its overall absorption exhibited a larger blue shift of $\sim 30 \mathrm{~nm}$ than the film cast without involving CN. These changes may result from the confined crystallization of FPIC6 during the chloroform evaporation in the presence of CN. Our results indicated that $\mathrm{CN}$ as an additive can effectively tune the crystallization behaviour of small molecule acceptor FPIC6, resulting in optimized morphology.

XRD (Fig. S7†) patterns firstly demonstrate an amorphous PTB7-Th donor polymer and crystalline FPIC6, respectively. Reading the diffractograms of the films of neat FPIC6 and PTB7Th:FPIC6 blends without CN, the same diffraction peak at $2 \theta=$ $7.95^{\circ}$, corresponding to the same $d$-spacing of $11.11 \AA$ for the crystal planes of FPIC6 and its blends with PTB7-Th without the additive of $\mathrm{CN}$, can be found, while the crystallinity of FPIC6 was clearly restricted by PTB7-Th. For the blend film with 1\% $\mathrm{CN}$, one broad diffraction peak ranging from $6.8-8.3^{\circ}$ is well pronounced. This may also confirm that there are both $\mathrm{H}-$ and Jaggregation in the blend film with $1 \% \mathrm{CN} .{ }^{52,53}$

Grazing incidence wide-angle X-ray scattering (GIWAXS) was also employed to furthermore investigate the molecular orientation of PFIC6 and PTB7-Th in their thin films (Fig. 3). The out- of-plane (OOP) diffractogram of the PTB7-Th neat film shows predominant face-on orientation with $\pi-\pi$ stacking distances of $3.99 \AA$, which agrees well with both an in-plane distinct diffraction peak at around $2.57 \mathrm{~nm}^{-1}$ for (100) and a less pronounced peak at $8.50 \mathrm{~nm}^{-1}$ for (200) representing its sidechain packing. As for the neat film of FPIC6, both diffractions at wide angles of ca. $q_{z} \sim 16.7 \mathrm{~nm}^{-1}$ (corresponding to its $\pi-\pi$ stacking distances of $3.75 \AA$ ) and $\sim 5.0 \mathrm{~nm}^{-1}$ are found in its OOP profile simultaneously, which suggests clearly the mixing of edge-on and faceon orientation of FPIC6. In the meantime, it also shows high crystallinity with the (100) diffraction peak at $q_{y} \sim 3.3 \mathrm{~nm}^{-1}$ and with clear high order diffraction peaks at $5.2 \mathrm{~nm}^{-1}$ for (200) and $6.6 \mathrm{~nm}^{-1}$ for (300) in the in-plane (IP) direction, revealing longrange order of the lamellar packing of FPIC6. For the blend films, either with or without $\mathrm{CN}$ as an additive, dominating faceon orientation was preserved with significantly reduced intensity of (100) diffraction peaks in the OOP direction. It is noteworthy that the (100) diffraction peak of the blend film with $1 \% \mathrm{CN}$ shifted to small $q$ values compared to that of the blend film without $\mathrm{CN}$, which might also result from the reduced packing/ aggregation. These can well explain the blue shift of EQE and absorption spectra by adding $\mathrm{CN}$.

As shown in Fig. S8, $\uparrow$ differential scanning calorimetry (DSC) studies revealed a cold crystallization peak at $217{ }^{\circ} \mathrm{C}$ and a melting peak at $251{ }^{\circ} \mathrm{C}$ for FPIC6 in the heating process, and two crystallization peaks at $231{ }^{\circ} \mathrm{C}$ and $235{ }^{\circ} \mathrm{C}$ upon cooling, confirming its crystalline structure. ${ }^{54-57}$ In contrast, when it is blended with amorphous PTB7-Th, the crystallization of FPIC6 (a)
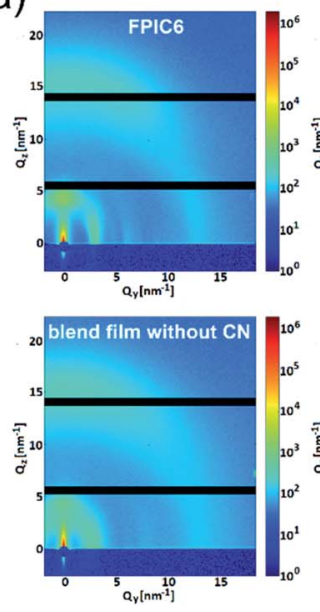

(b)

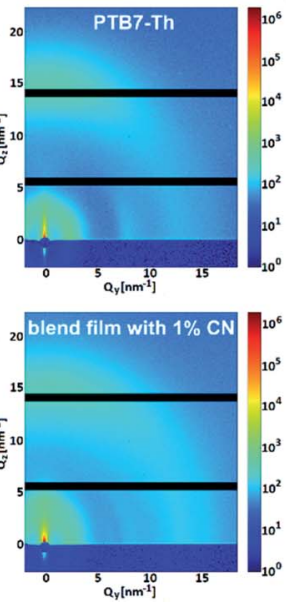

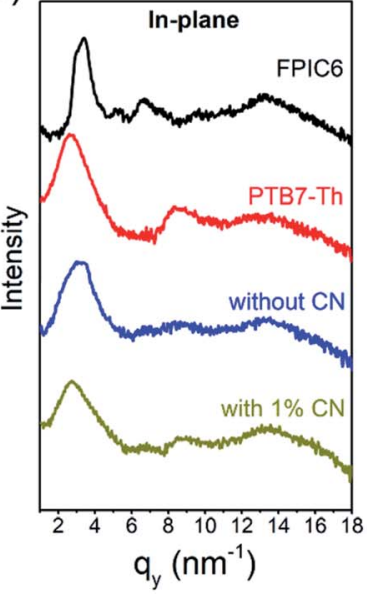

(c)

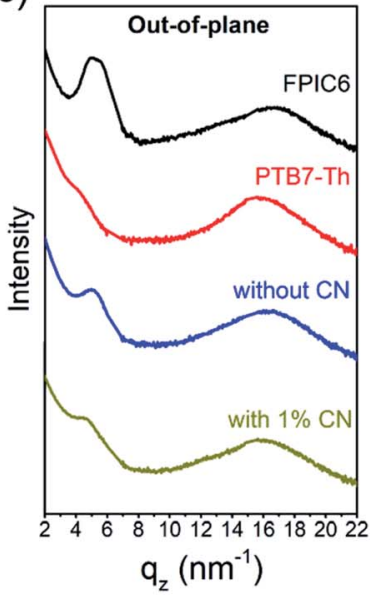

Fig. 3 GIWAXS images (a), in-plane (b), and out-of-plane (c) scattering profiles for neat and PTB7-Th:FPIC6 blend films. 
turned to be remarkably restricted either in the absence or presence of CN, due to the strong interference of PTB7-Th on the $\pi-\pi$ stacking of FPIC6 as discussed above.

\subsection{PL quenching and exciton lifetimes}

Correspondingly, the PTB7-Th:FPIC6 blend film cast from chloroform with $1 \% \mathrm{CN}$ also showed higher photoluminescence (PL) quenching efficiency compared to the blend film evaporated without $\mathrm{CN}$ (Fig. S9†), regardless of the excitation wavelength located at the absorption maximum of PTB7-Th or FPIC6, indicating that the active layer with $1 \% \mathrm{CN}$ has more efficient photo-induced exciton dissociation and charge transport behaviour. The exciton dissociation was studied by timeresolved photoluminescence (TR-PL) measurements with photoexcitation at an excitation wavelength of $780 \mathrm{~nm}$, whose photon flux is $8.3 \times 10^{12}$ photons per $\mathrm{cm}^{2}$. The monitored emission is at the wavelength integrated from 820 to $880 \mathrm{~nm}$. As shown in Fig. 4, the blend films show much shorter exciton lifetimes $(\tau)$ compared to that of neat FPIC6 films (134 ps), due to the photoinduced charge transfer in the excited state. ${ }^{\mathbf{5 8}}$

\subsection{Charge carrier mobilities and morphology}

Hole and electron mobilities of PTB7-Th:FPIC6 blend films were measured by the space-charge limited current (SCLC) method (Fig. S10 and Table S3†). The PTB7-Th:FPIC6 blend film with 1\% CN shows an electron mobility of $6.2 \times 10^{-5} \mathrm{~cm}^{2} \mathrm{~V}^{-1} \mathrm{~s}^{-1}$, which is twice higher than that of the blend film without CN. Thus, the active layer cast with $1 \% \mathrm{CN}$ exhibited more balanced charge carrier transport and enhanced $\mathrm{FF}$ as mentioned above.

In order to understand the effect of the addition of $1 \% \mathrm{CN}$, the surface and bulk morphologies of the blend films were also studied by atomic force microscopy (AFM) and transmission electron microscopy (TEM). AFM images in Fig. 5 and S11† indicate that the film without CN shows tiny FPIC6 crystals in the film with a large RMS roughness of $7.09 \mathrm{~nm}$, while the film with $1 \% \mathrm{CN}$ shows fine and smooth structures, and the RMS roughness was also reduced to $1.03 \mathrm{~nm}$. In the TEM images shown in Fig. 5, unlike the film without 1\% CN exhibiting large

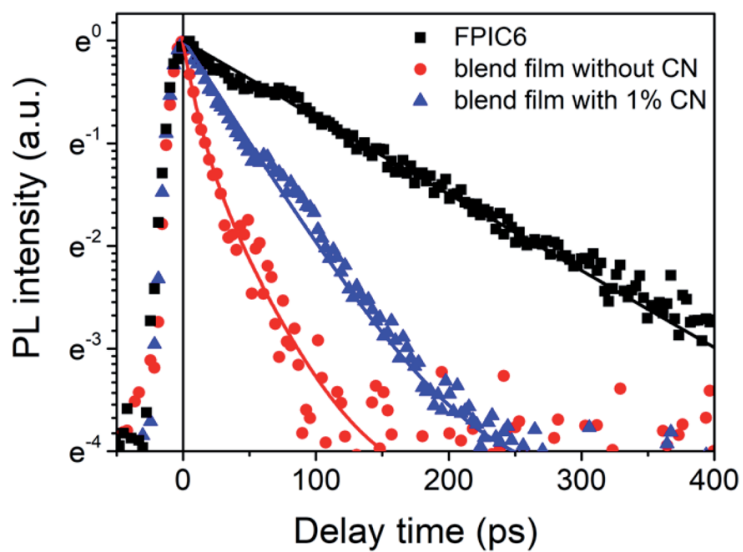

Fig. 4 Time-resolved PL decay spectra of FPIC6 and PTB7-Th:FPIC6 blend films.
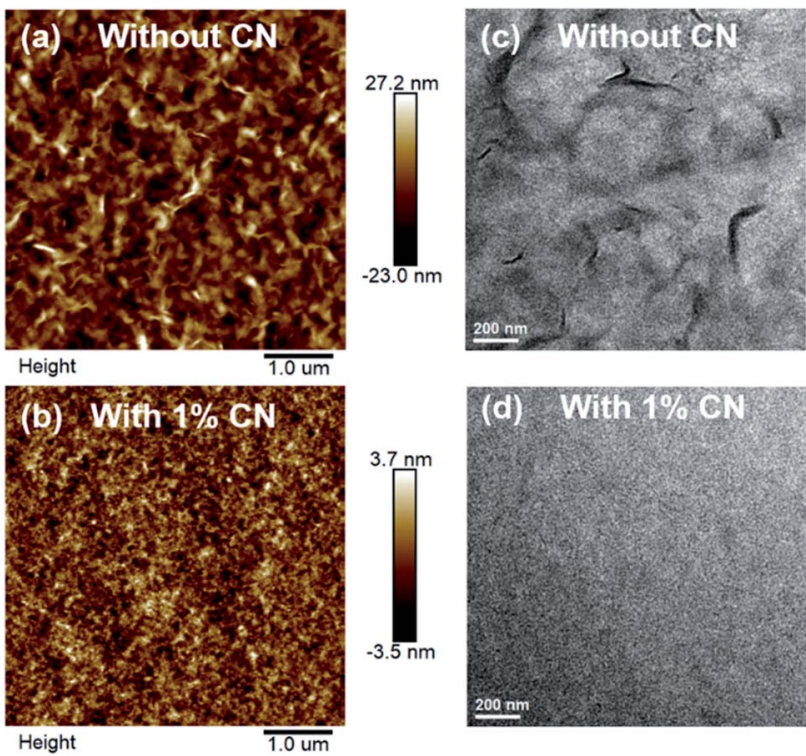

Fig. 5 ( $a$ and $b)$ AFM height images and ( $c$ and d) TEM images of PTB7Th:FPIC6 blend films without CN (above) and with 1\% CN (bottom).

domain features, the film with $1 \% \mathrm{CN}$ was quite uniform and exhibited good miscibility, which agrees quite well with the AFM images. These results indicate that the addition of $1 \% \mathrm{CN}$ can reduce large crystals from FPIC6 and increase the miscibility of the two components, which is beneficial for increasing $\mathrm{D} / \mathrm{A}$ interface areas and effective exciton dissociation, leading to much higher $J_{\mathrm{SC}}$ and FF.

\section{Experimental section}

All reagents were purchased from Alfa Aesar Co., Aladdin Co., Derthon Co. and other commercial suppliers. 1,6-Bis $(4,4,5,5-$ tetramethyl-1,3,2-dioxaborolan-2-yl)pyrene (1) and ethyl 2-bromothieno[3,2- $b]$ thiophene-3-carboxylate were prepared according to the literature..$^{35,59}$

\subsection{Synthesis of diethyl $2,2^{\prime}$-(pyrene-1,6-diyl)bis(thieno[3,2-} b]thiophene-3-carboxylate) (2)

A mixture of ethyl 2-bromothieno[3,2-b]thiophene-3-carboxylate (1.18 g, $4.05 \mathrm{mmol}$ ) and compound 1 (735 $\mathrm{mg}, 1.62 \mathrm{mmol})$ in a mixed solution of toluene $(35 \mathrm{~mL}) /$ ethanol $(15 \mathrm{~mL}) / \mathrm{K}_{2} \mathrm{CO}_{3}$ aqueous solution $\left(2 \mathrm{M}, 15 \mathrm{~mL}\right.$ ) was degassed before $\mathrm{Pd}\left(\mathrm{PPh}_{3}\right)_{4}$ (100 $\mathrm{mg}, 0.09 \mathrm{mmol}$ ) was added. The mixture was heated to reflux for $24 \mathrm{~h}$, and then cooled to room temperature. After filtration, compound 2 was obtained as a yellow solid $(894 \mathrm{mg}$, 88.7\%). ${ }^{1} \mathrm{H}$ NMR (500 MHz, $\left.\mathrm{CDCl}_{3}, \delta / \mathrm{ppm}\right): 8.22$ (d, $J=7.1 \mathrm{~Hz}$, 2H), 8.10-8.06 (m, 4H), 7.57 (d, $J=5.0 \mathrm{~Hz}, 2 \mathrm{H}), 7.38$ (d, $J=$ $5.0 \mathrm{~Hz}, 2 \mathrm{H}), 7.19$ (d, $J=7.5 \mathrm{~Hz}, 2 \mathrm{H}), 3.98$ (br, $4 \mathrm{H}), 0.68$ (br, 6H).

\subsection{Synthesis of compound 4}

To a solution of 1-bromo-4-hexylbenzene (2.07 $\mathrm{g}, 8.58 \mathrm{mmol})$ in $50 \mathrm{~mL}$ of $\mathrm{THF}$ at $-78{ }^{\circ} \mathrm{C}$ was added $n$-BuLi $(3.4 \mathrm{~mL}, 2.5 \mathrm{M}$ in hexane) under nitrogen. The mixture was kept at $-78^{\circ} \mathrm{C}$ for $1 \mathrm{~h}$, 
and then compound 2 ( $894 \mathrm{mg}, 1.44 \mathrm{mmol}$ ) was added. The mixture was stirred at room temperature overnight and then poured into water and extracted twice with ethyl acetate. After removing the solvent, the crude compound 3 was dissolved in $50 \mathrm{~mL}$ dry toluene and $1.0 \mathrm{~g}$ Amberlyst 15 was added, and then the mixture was refluxed for $6 \mathrm{~h}$ under nitrogen. After cooling to room temperature, the mixture was filtered and the solvent was removed. The crude product was purified by column chromatography on silica gel using a mixture of petroleum ether/ dichloromethane $(10: 1, \mathrm{v} / \mathrm{v})$ as the eluent to give compound 4 as an orange solid (386 mg, 23.5\%). ${ }^{1} \mathrm{H}$ NMR (400 $\mathrm{MHz}, \mathrm{CDCl}_{3}, \delta /$ ppm): 8.02 (d, $J=8.0 \mathrm{~Hz}, 2 \mathrm{H}), 7.96(\mathrm{~d}, J=8.1 \mathrm{~Hz}, 2 \mathrm{H}), 7.88(\mathrm{~s}, 2 \mathrm{H})$, $7.22-7.17$ (m, 12H), $7.03(\mathrm{~d}, J=8.3 \mathrm{~Hz}, 8 \mathrm{H}), 2.56-2.49(\mathrm{~m}, 8 \mathrm{H})$, 1.56-1.51 (m, 8H), 1.33-1.25 (m, 24H), 0.88-0.83 (m, 12H). ${ }^{13} \mathrm{C}$ NMR (125 MHz, $\left.\mathrm{CDCl}_{3}, \delta / \mathrm{ppm}\right): 142.35,141.23,141.04,137.44$, 136.69, 135.05, 130.37, 129.49, 129.32, 127.78, 127.55, 125.87, 125.39, 123.29, 120.21, 118.65, 57.99, 34.96, 31.21, 30.72, 29.23, 28.49, 22.11, 13.60. MS (MALDI-TOF, $m / z): ~ 1142.605$.

\subsection{Synthesis of compound 5}

To a solution of compound 4 (150 mg, $0.13 \mathrm{mmol}), 2 \mathrm{~mL}$ of DMF, and $30 \mathrm{~mL}$ of 1,2-dichloroethane at $0{ }^{\circ} \mathrm{C}$ was added $\mathrm{POCl}_{3}(0.24$ $\mathrm{mL}, 2.62 \mathrm{mmol}$ ) under nitrogen. The mixture was kept at $0{ }^{\circ} \mathrm{C}$ for $0.5 \mathrm{~h}$, and then was heated to $85^{\circ} \mathrm{C}$ for $24 \mathrm{~h}$. After cooling to room temperature, $100 \mathrm{~mL} \mathrm{NaHCO}_{3}$ aqueous solution was added and the mixture was extracted with dichloromethane. After removal of the solvent, the crude product was purified by column chromatography on silica gel using a mixture of petroleum ether/ dichloromethane $(2: 1, \mathrm{v} / \mathrm{v})$ as the eluent to give compound 5 as a red solid (132 mg, 84.1\%). ${ }^{1} \mathrm{H}$ NMR (500 $\mathrm{MHz} \mathrm{CDCl}_{3}, \delta /$ ppm): 9.85 (s, 2H), 8.09 (d, $J=8.0 \mathrm{~Hz}, 2 \mathrm{H}), 8.04(\mathrm{~d}, J=8.1 \mathrm{~Hz}, 2 \mathrm{H})$, $7.88(\mathrm{~s}, 2 \mathrm{H}), 7.85(\mathrm{~s}, 2 \mathrm{H}), 7.16(\mathrm{~d}, J=8.3 \mathrm{~Hz}, 8 \mathrm{H}), 7.05(\mathrm{~d}, J=$ $8.3 \mathrm{~Hz}, 8 \mathrm{H}), 2.61-2.50(\mathrm{~m}, 8 \mathrm{H}), 1.59-1.53(\mathrm{~m}, 8 \mathrm{H}), 1.36-1.22(\mathrm{~m}$, $24 \mathrm{H}), 0.85$ (t, $J=6.7 \mathrm{~Hz}, 12 \mathrm{H})$. MS (MALDI-TOF, $m / z): 1199.473$.

\subsection{Synthesis of FPIC6}

To a solution of compound 5 (164 mg, $0.14 \mathrm{mmol}), 2-(5,6-$ difluoro-3-oxo-2,3-dihydro-1 $H$-inden-1-ylidene)malononitrile (2FIC, $158 \mathrm{mg}, 0.68 \mathrm{mmol}$ ), and $50 \mathrm{~mL}$ chloroform was added $1 \mathrm{~mL}$ pyridine under nitrogen. The mixture was heated to reflux for $16 \mathrm{~h}$. After cooling to room temperature, the mixture was poured into $150 \mathrm{~mL}$ methanol and filtered. The crude product was purified by column chromatography on silica gel using a mixture of petroleum ether/dichloromethane $(1: 3, \mathrm{v} / \mathrm{v})$ as the eluent to give FPIC6 as a black solid (171 mg, 77.0\%). ${ }^{1} \mathrm{H}$ NMR (400 MHz, $\left.\mathrm{CDCl}_{3}, \delta / \mathrm{ppm}\right): 8.71(\mathrm{~s}, 2 \mathrm{H}), 8.51-8.47$ (m, 2H), 8.17 $(\mathrm{s}, 2 \mathrm{H}), 8.13(\mathrm{~d}, J=8.1 \mathrm{~Hz}, 2 \mathrm{H}), 8.07$ (d, $J=8.2 \mathrm{~Hz}, 2 \mathrm{H}), 7.97$ (s, 2H), 7.61 (m, 2H), 7.24-7.20 (m, 8H), 7.12-7.10 (m, 8H), 2.60$2.53(\mathrm{~m}, 8 \mathrm{H}), 1.63-1.52(\mathrm{~m}, 8 \mathrm{H}), 1.31-1.20$ (m, 24H), 0.84-0.77 (m, 12H). IR: $v=2216 \mathrm{~cm}^{-1}(\mathrm{C} \equiv \mathrm{N}), 1700 \mathrm{~cm}^{-1}(\mathrm{C}=\mathrm{O}) . \mathrm{MS}$ (MALDI-TOF, $\mathrm{m} / \mathrm{z}$ ): 1622.687 .

\section{Conclusions}

In summary, using pyrene fused with two thieno[3,2- $b]$ thiophenes via its $[f-g, m-n]$ bay-position (1,8-position) as six- membered ring bridges as the core, and 2-(5,6-difluoro-3-oxo2,3-dihydro- $1 H$-inden-1-ylidene)malononitrile (2FIC) as the end-groups, a non-coplanar small molecule acceptor FPIC6 has been designed and successfully synthesized. Compared with its isomer FPIC5 with five-membered ring bridges via the $[a, h]$ ortho-position at 2,9-positions, FPIC6 with a more fused core and improved connectivity exhibits a $119 \mathrm{~nm}$ red-shifted absorption peak in films and a much narrower $E_{\mathrm{g}}^{\mathrm{opt}}$ of $1.42 \mathrm{eV}$. FPIC6 possesses a slightly higher LUMO energy level $(-3.91 \mathrm{eV})$, but a much higher HOMO energy level of $-5.44 \mathrm{eV}$ than those of its structural isomer FPIC5. By adding $1 \% \mathrm{CN}$ as the processing additive, the PCE of PTB7-Th:FPIC6 solar cells was improved from $9.11 \%$ to $11.55 \%$, with a $V_{\mathrm{OC}}$ of $0.79 \mathrm{~V}$, a $J_{\mathrm{SC}}$ of $21.50 \mathrm{~mA}$ $\mathrm{cm}^{-2}$, and a FF of 0.67 . It is obvious that the better photoluminescence quenching behaviour, more balanced charge carrier mobilities, and optimal morphology are responsible for the much better photovoltaic performance due to the use of $\mathrm{CN}$ as the additive. In contrast, solar cells based on PTB7-Th:FPIC5 just achieved a PCE of $8.45 \%$. Our results clearly confirm such 1,8-position connectivity on the pyrene core as the crucial origin of the lowered bandgap and the improved photocurrent and PCE for FPIC6. This strongly indicates that such position dependent connectivity can be a key-design strategy for future A-D-A type narrow bandgap NFAs in common.

\section{Conflicts of interest}

There are no conflicts to declare.

\section{Acknowledgements}

E. Wang thanks the Swedish Research Council, the Swedish Research Council Formas, and the Wallenberg Foundation (2017.0186 and 2016.0059) for financial support. J. Cao acknowledges financial support from the National Natural Science Foundation of China (21604021), China Scholarship Council (CSC, 201808430041), and Hunan Provincial Natural Science Foundation (2018JJ3141). M. Zhang acknowledges financial support from the National Natural Science Foundation of China (NSFC) (No. 51573120, 51773142 and 91633301) and the Collaborative Innovation Center of Suzhou Nano Science \& Technology. X. Zou appreciates the financial support from the China Scholarship Council (201608440294). C. J. Brabec and N. Li acknowledge the funding from the DFG research grant (BR 4031/13-1) and SFB 953 (Project No. 182849149). D. Yu acknowledges the financial support from Innovation fund Denmark (INKA project) and Sino-Danish Centre for Education and Research (SDC). W. Gruber and T. Unruh gratefully acknowledge the funding of the Deutsche Forschungsgemeinschaft (DFG) through INST 90/825-1 FUGG, INST 90/751-1 FUGG, and INST 90/827-1 FUGG, the "Cluster of Excellence Engineering of Advanced Materials (EAM)”, the research training group GRK 1896 "In Situ Microscopy with Electrons, X-rays and Scanning Probes”, the research unit FOR 1878 "Functional Molecular Structures on Complex Oxide Surfaces" and the German Federal Ministry of Education and Research (BMBF, project numbers: 05K16WEB and 05K16WE1). 
The authors thank the valuable help from Prof. Xiaowei Zhan at Peking University, Prof. Yanming Sun at Beihang University, and Chalmers Materials Analysis Laboratory (CMAL).

\section{Notes and references}

1 Y. Lin, J. Wang, Z.-G. Zhang, H. Bai, Y. Li, D. Zhu and X. Zhan, Adv. Mater., 2015, 27, 1170.

2 Y. Lin, Z.-G. Zhang, H. Bai, J. Wang, Y. Yao, Y. Li, D. Zhu and X. Zhan, Energy Environ. Sci., 2015, 8, 610.

3 W. Zhao, S. Li, H. Yao, S. Zhang, Y. Zhang, B. Yang and J. Hou, J. Am. Chem. Soc., 2017, 139, 7148.

4 Y. Wang, Y. Zhang, N. Qiu, H. Feng, H. Gao, B. Kan, Y. Ma, C. Li, X. Wan and Y. Chen, Adv. Energy Mater., 2018, 8, 1702870.

5 Z. Luo, H. Bin, T. Liu, Z.-G. Zhang, Y. Yang, C. Zhong, B. Qiu, G. Li, W. Gao, D. Xie, K. Wu, Y. Sun, F. Liu, Y. Li and C. Yang, Adv. Mater., 2018, 30, 1706124.

6 J. Wang, J. Zhang, Y. Xiao, T. Xiao, R. Zhu, C. Yan, Y. Fu, G. Lu, X. Lu, S. R. Marder and X. Zhan, J. Am. Chem. Soc., 2018, 140, 9140.

7 Y. Yang, Z.-G. Zhang, H. Bin, S. Chen, L. Gao, L. Xue, C. Yang and Y. Li, J. Am. Chem. Soc., 2016, 138, 15011.

8 C. Yan, S. Barlow, Z. Wang, H. Yan, A. K.-Y. Jen, S. R. Marder and X. Zhan, Nat. Rev. Mater., 2018, 3, 18003.

9 P. Cheng, G. Li, X. Zhan and Y. Yang, Nat. Photonics, 2018, 12, 131.

10 T. Li, S. Dai, Z. Ke, L. Yang, J. Wang, C. Yan, W. Ma and X. Zhan, Adv. Mater., 2018, 30, 1705969.

11 R. Yu, H. Yao and J. Hou, Adv. Energy Mater., 2018, 8, 1702814.

12 D. He, F. Zhao, L. Jiang and C. Wang, J. Mater. Chem. A, 2018, 6, 8839.

13 Z. Xiao, S. Yang, Z. Yang, J. Yang, H.-L. Yip, F. Zhang, F. He, T. Wang, J. Wang, Y. Yuan, H. Yang, M. Wang and L. Ding, Adv. Mater., 2019, 31, 1804790.

14 J. Yuan, Y. Zhang, L. Zhou, G. Zhang, H.-L. Yip, T.-K. Lau, X. Lu, C. Zhu, H. Peng, P. A. Johnson, M. Leclerc, Y. Cao, J. Ulanski, Y. Li and Y. Zou, Joule, 2019, 3, 1140.

15 H. Wu, H. Fan, S. Xu, L. Ye, Y. Guo, Y. Yi, H. Ade and X. Zhu, Small, 2019, 15, 1804271.

16 Y. Li, L. Zhong, J.-D. Lin, F.-P. Wu, H.-J. Bin, Z. Zhang, L. Xu, Z.-Q. Jiang, Z.-G. Zhang, F. Liu, T. P. Russell, Y. Li, L.-S. Liao and S. R. Forrest, Sol. RRL, 2017, 1, 1700107.

17 F. Liu, Z. Zhou, C. Zhang, T. Vergote, H. Fan, F. Liu and X. Zhu, J. Am. Chem. Soc., 2016, 138, 15523.

18 B. Fan, D. Zhang, M. Li, W. Zhong, Z. Zeng, L. Ying, F. Huang and Y. Cao, Sci. China: Chem., 2019, 62, 746.

19 Q. Liu, Y. Jiang, K. Jin, J. Qin, J. Xu, W. Li, J. Xiong, J. Liu, Z. Xiao, K. Sun, S. Yang, X. Zhang and L. Ding, Sci. Bull., 2020, 65, 272.

20 Y. Chang, T.-K. Lau, M.-A. Pan, X. Lu, H. Yan and C. Zhan, Mater. Horiz., 2019, 6, 2094.

21 L. Meng, Y. Zhang, X. Wan, C. Li, X. Zhang, Y. Wang, X. Ke, Z. Xiao, L. Ding, R. Xia, H.-L. Yip, Y. Cao and Y. Chen, Science, 2018, 361, 1094.
22 O. P. Lee, A. T. Yiu, P. M. Beaujuge, C. H. Woo, T. W. Holcombe, J. E. Millstone, J. D. Douglas, M. S. Chen and J. M. J. Fréchet, Adv. Mater., 2011, 23, 5359.

23 H. Huang, L. Xiao, B. Yang, T. Lai, L. Zhang, K. Gao, X. Peng and Y. Cao, RSC Adv., 2016, 6, 59218.

24 S.-S. Li, K.-J. Jiang, C.-C. Yu, J.-H. Huang, L.-M. Yang and Y.-L. Song, New J. Chem., 2014, 38, 4404.

25 D. Yu, Y. Liu, M. Xiao, Q. Fan, W. Su, X. Li, H. Tan, Y. Wang, R. Yang and W. Zhu, Dyes Pigm., 2016, 125, 151.

26 K. Oniwa, H. Kikuchi, H. Shimotani, S. Ikeda, N. Asao, Y. Yamamoto, K. Tanigaki and T. Jin, Chem. Commun., 2016, 52, 4800.

27 Y. Gong, X. Zhan, Q. Li and Z. Li, Sci. China: Chem., 2016, 59, 1623.

28 T. M. Figueira-Duarte and K. Müllen, Chem. Rev., 2011, 111, 7260.

29 Q. Fan, Y. Liu, M. Xiao, H. Tan, Y. Wang, W. Su, D. Yu, R. Yang and W. Zhu, Org. Electron., 2014, 15, 3375.

30 N. J. Jeon, J. Lee, J. H. Noh, M. K. Nazeeruddin, M. Gratzel and S. I. Seok, J. Am. Chem. Soc., 2013, 135, 19087.

31 J.-H. Kim, H. U. Kim, I.-N. Kang, S. K. Lee, S.-J. Moon, W. S. Shin and D.-H. Hwang, Macromolecules, 2012, 45, 8628.

32 G. Cai, P. Xue, Z. Chen, T. Li, K. Liu, W. Ma, J. Lian, P. Zeng, Y. Wang, R. P. S. Han and X. Zhan, Chem. Mater., 2019, 31, 6484.

33 J. Wu, Y. Chen, B. Hu, Z. Pang, Z. Lu and Y. Huang, Chem.Eur. J., 2019, 25, 6385.

34 Y. Wang, B. Liu, C. W. Koh, X. Zhou, H. Sun, J. Yu, K. Yang, H. Wang, Q. Liao, H. Y. Woo and X. Guo, Adv. Energy Mater., 2019, 9, 1803976.

35 X. Wang, L. Feng and L. Zhang, Dyes Pigm., 2013, 97, 318.

36 X. Xu, Z. Li, Z. Bi, T. Yu, W. Ma, K. Feng, Y. Li and Q. Peng, Adv. Mater., 2018, 30, 1800737.

37 Y. Liu, Z. Zhang, S. Feng, M. Li, L. Wu, R. Hou, X. Xu, X. Chen and Z. Bo, J. Am. Chem. Soc., 2017, 139, 3356.

38 Z. Xiao, X. Jia and L. Ding, Sci. Bull., 2017, 62, 1562.

39 Y. Li, N. Zheng, L. Yu, S. Wen, C. Gao, M. Sun and R. Yang, Adv. Mater., 2019, 31, 1807832.

40 J. Yu, J. Cao, H. Tan, W. Peng, Y. Wang and W. Zhu, Dyes Pigm., 2017, 141, 21.

41 W. Peng, G. Zhang, L. Shao, C. Ma, B. Zhang, W. Chi, Q. Peng and W. Zhu, J. Mater. Chem. A, 2018, 6, 24267.

42 J. Sun, X. Ma, Z. Zhang, J. Yu, J. Zhou, X. Yin, L. Yang, R. Geng, R. Zhu, F. Zhang and W. Tang, Adv. Mater., 2018, 30, 1707150.

43 W. Hu, Z. Zhang, Y. Xu, J. Cao, S. Liu, Z. Tang, B. Zhao and J. Zhang, J. Mater. Chem. C, 2018, 6, 6911.

44 J. Cao, C. Zuo, J. Yu and Z. Tang, Dyes Pigm., 2017, 139, 201. 45 X. Shi, L. Zuo, S. B. Jo, K. Gao, F. Lin, F. Liu and A. K.-Y. Jen, Chem. Mater., 2017, 29, 8369.

46 C. J. Lambert and S.-X. Liu, Chem.-Eur. J., 2018, 24, 4193.

47 D. Veldman, S. C. J. Meskers and R. A. J. Janssen, Adv. Funct. Mater., 2009, 19, 1939.

48 Z. Yao, X. Liao, K. Gao, F. Lin, X. Xu, X. Shi, L. Zuo, F. Liu, Y. Chen and A. K.-Y. Jen, J. Am. Chem. Soc., 2018, 140, 2054. 49 W.-Y. Tan, K. Gao, J. Zhang, L.-L. Chen, S.-P. Wu, X.-F. Jiang, X.-B. Peng, Q. Hu, F. Liu, H.-B. Wu, Y. Cao and X.-H. Zhu, Sol. $R R L, 2017,1,1600003$. 
50 M. Más-Montoya and R. A. J. Janssen, Adv. Funct. Mater., 2017, 27, 1605779.

51 S. ong Kim, T. K. An, J. Chen, I. Kang, S. H. Kang, D. S. Chung, C. E. Park, Y.-H. Kim and S.-K. Kwon, Adv. Funct. Mater., 2011, 21, 1616.

52 Q. Zhao, J. Liu, H. Wang, M. Li, K. Zhou, H. Yang and Y. Han, J. Mater. Chem. C, 2015, 3, 8183.

53 Q. Zhao, X. Yu, J. Liu, Z. Xie and Y. Han, Org. Electron., 2016, $37,6$.

54 S. Holliday, R. S. Ashraf, A. Wadsworth, D. Baran, S. A. Yousaf, C. B. Nielsen, C.-H. Tan, S. D. Dimitrov, Z. Shang, N. Gasparini, M. Alamoudi, F. Laquai,
C. J. Brabec, A. Salleo, J. R. Durrant and I. McCulloch, Nat. Commun., 2016, 7, 11585.

55 Y. Li, N. Zheng, L. Yu, S. Wen, C. Gao, M. Sun and R. Yang, Adv. Mater., 2019, 31, 1807832.

56 T. J. Aldrich, M. Matta, W. Zhu, S. M. Swick, C. L. Stern, G. C. Schatz, A. Facchetti, F. S. Melkonyan and T. J. Marks, J. Am. Chem. Soc., 2019, 141, 3274.

57 P. Yin, T. Zheng, Y. Wu, G. Liu, Z.-G. Zhang, C. Cui, Y. Li and P. Shen, J. Mater. Chem. A, 2018, 6, 20313.

58 Z. Li, W. Zhang, X. Xu, Z. Genene, D. Di Carlo Rasi, W. Mammo, A. Yartsev, M. R. Andersson, R. A. J. Janssen and E. Wang, Adv. Energy Mater., 2017, 7, 1602722.

59 D. He, L. Qian and L. Ding, Polym. Chem., 2016, 7, 2329. 